\title{
Costa Versus Enel - O Primado do Direito Comunitário e a Mudança de Paradigma: o Estado em Rede Europeu
}

\author{
Costa Versus Enel - The Primacy of the \\ Community LaW and the Change of \\ Paradigm: the State in European Rede
}

\author{
Suélen Farenzena *
}

Resumo: O presente texto tem por objetivo analisar a construção do primado do direito comunitário que tomou forma a partir do acórdão Costa versus ENEL. O estudo propõe-se a contextualizar as transformações que passaram os Estados e o processo de integração que emergiu, para, com isso, reunir condições de apresentar a construção jurisprudencial que consagrou o primado do direito comunitário, rompendo o paradigma da supremacia constitucional. Buscar-se-á, por fim, avaliar qual é, então, o papel dos Estados nesse complexo conjunto e de suas respectivas Constituições.

Palavras-chave: Processo de Integração. Primado do Direito Comunitário. Estado em Rede.

Abstract: The present text has for objective to analyze the construction of the primate of the European Community law that took form from the sentence Coast versus ENEL. The study it is considered to contextualizar the transformations that had passed the States and the process of integration that emerged, for, with this, to congregate conditions to present the jurisprudencial construction that consecrated the primate of the European Community law, breaching the paradigm of the constitutional supremacy. One will search, finally, to evaluate which is, then, the paper of the States in this joint complex and of its respective Constitutions.

* Mestre em Direito Público pela Universidade do Vale do Rio dos Sinos. Graduada em Direito pela Universidade de Caxias do Sul. Colaboradora do Projeto de Pesquisa Globalização Econômica e Análise Econômica do Direito. $\mathrm{E}-\mathrm{m} \quad \mathrm{a} \quad \mathrm{i} \quad \mathrm{l}$ : suellenfarenzena@yahoo.com.br
Keywords: Process of Integration. Primate of the European Community law. State in Rede. 


\section{INTRODUÇÃO}

O presente texto tem por escopo analisar qual deve ser o papel a ser desempenhado pelos Estados nacionais e suas respectivas Constituições diante do rompimento de paradigma ocasionado pelo desenvolvimento do direito comunitário.

O fato é que nem sempre foi feita uma clara distinção entre as questões mais estritamente ligadas à organização institucional da União Européia e aquelas relativas às relações entre a União e os Estados-membros individuais, em especial quanto à verdadeira revolução normativa e institucional introduzida pela predominância dos poderes supranacionais sobre os poderes soberanos de cada Estado, circunstância que justifica o presente estudo.

Para isso, inicialmente, contextualiza-se as transformações que passaram os Estados e o avançado processo de integração que acabou por tomar forma no âmbito da União Européia (1). Sucede que os blocos econômicos surgem, em princípio, com o objetivo de promover acordos fiscais e alfandegários entre os Estados, de modo que a economia dos mesmos seja estimulada e isso possa favorecer o seu crescimento. Entretanto, o bloco formado pela União Européia, desenvolveu-se e consolidou-se de tal forma que criou uma verdadeira comunidade supranacional, provocando a inocuidade das clássicas visões. Com o reconhecimento da aplicabilidade direta ao direito comunitário como um todo, restou necessário estabelecer-se qual deveria ser a relação entre este e o direito nacional. Em caso de haver normas contraditórias provenientes de cada um deles, ambas diretamente aplicáveis, surgia o problema de estabelecer qual prevaleceria.

Busca-se, então, apresentar a construção jurisprudencial que consagrou o primado do direito comunitário, rompendo o paradigma da supremacia constitucional (2). Como restou consignado, os Estados-membros limitaram, embora em domínios restritos, os seus direitos soberanos e criaram, assim, um corpo de direito aplicável aos seus súbditos e a eles próprios. Essa integração no direito de cada país membro, de disposições provenientes de fonte comunitária, e, mais genericamente, os termos e o espírito do Tratado têm por corolário a impossibilidade para os Estados-membros de fazer prevalecer, contra uma ordem jurídica por eles aceite numa base de reciprocidade, uma medida unilateral. Com isso, emerge o questionamento: a dupla Estado Nacional-Constituição perdeu definitivamente e irreversivelmente seu significado, sendo relegada ao plano de instrumento de análise histórico-institucional ou está na hora de apartar 
o conceito histórico de Constituição à peculiaridade da situação européia, que certamente coloca-se num plano distinto daquele das peculiaridades nacionais?

Visando discutir esse tema, acerca de qual seria o papel dos Estados nesse complexo conjunto e de suas respectivas Constituições (3), apresenta-se a teoria do Estado em rede, enquanto europeização das Constituições nacionais, por um lado, e formação de um nível mais alto e comum de direito constitucional. O Estado na modernidade não é, pois, eliminado, mas redefinido. Através do compartilhamento de autoridade, articula-se numa rede com instituições supranacionais de tipos e âmbitos diferentes, com instituições locais e regionais e com organizações não-governamentais. O aparato burocrático do Estado não mais constitui, nesse sentido, o único caminho de interação, como será demonstrado.

\section{O ESTADO E O PROCESSO DE INTEGRAÇÃO}

Na Idade Média, ainda não era possível falar em Estado como o mesmo se apresenta atualmente (senão de maneira embrionária), porque o poder político estava fragmentado entre os reinos, a Igreja e os senhores feudais. O Estado acabou sendo resultado, nesses termos, da centralização do poder na figura do rei, após a destruição do feudalismo e a quebra da autoridade da Igreja através da laicização do direito. Na sua origem, portanto, há a supremacia do poder (soberania) encarnada na pessoa do rei (em caráter absolutista). Na seqüência, com o liberalismo e a Revolução Francesa, o Estado adquire aspectos constitucionais e democráticos, transformando-se no dito Estado moderno (séculos XVI e XVII). (STELZER, 2000, p.79).

A história do constitucionalismo é, assim, siamesa da do moderno Estadonação democrático. Estado-nação e Constituição percorreram, de mãos dadas, toda a modernidade. Paradoxalmente, vai ser sobre as ondas de choque deste apogeu que a Constituição do Estado-nação democrático entra em crise na pós-modernidade e começa a sofrer de anomia, claustrofobia e endotropia. ${ }^{1}$ Com a globalização, pêndulo desta ruptura histórica, a Constituição deixa de ser o fecho e a chave do mundo político-jurídico para resistir sobretudo como seu alicerce e piso térreo.

\footnotetext{
${ }^{1} \mathrm{O}$ Estado enquanto modelo de unidade política, enquanto portador do que era o mais surpreendente de todos os monopólios, a saber, o monopólio da decisão política, verdadeira obra prima da tradição européia e do racionalismo ocidental, foi destronado. Se essas noções sobrevivem enquanto noções clássicas, a verdade é que esse mundo clássico aparece hoje como ambíguo, para não dizer irônico (PIRES, 1997, p.7-8).
} 
O fato é que o papel do Estado como protagonista dos fenômenos de transformação (da inovação científico-tecnológica aos centros de decisão administrativa e política) entra em crise como conseqüência da evolução dos seus elementos tradicionalmente constitutivos. (AMIRANTE, 2003, p.12). O povo apresenta-se cada vez menos vinculado aos rígidos componentes religiosos, lingüísticos e étnicos, que no passado representavam a quintessência da nação. O território acaba cada vez mais aberto a interferência e poderes de centros decisórios supranacionais e multinacionais. E o ordenamento jurídico, como resultado, cada vez menos expressão de um poder soberano exclusivo e indivisível.

Ocorre que o liberalismo econômico que começa a vicejar, por sua vez, lança o Estado liberal. A política e o direito vão atrás da economia e da informação, por um lado para recuperar o processo de desenvolvimento e modernização, por outro, para estabilizar os abalos tectônicos causados à segurança jurídica e política por uma mundialização irreversível e célere. $O$ Estado continua a ter um valor insubstituível e fundamental. Só que mesmo para ser eficaz intra-muros precisa ressegurar as suas funções mais além. Para defesa de si próprio, tem de evitar a abertura de um hiato para lá da sua alçada. (PIRES, 1997, p.13-14).

Veja-se que o Estado europeu do pós-guerra não tinha condições de reerguer-se sozinho, de participar da guerra fria singularmente ou de competir na globalização econômica. A falta de condição para diligenciar soberanamente estava evidenciada. A empresa européia traduziu, desse modo, a necessidade de uma união com vistas a sua sobrevivência no palco internacional. A soberania, com apenas algumas limitações ${ }^{2}$, pareceu mais atraente à maioria dos governos do que a submissão à hegemonia de qualquer grande potência. Isso ocasionou, de fato, um aumento, ao invés da redução, da capacidade e do prestígio. Sob qualquer ângulo que se examine, o Estado, nascido sob a forma de sociedade nacional, inicia um amplo processo de inserção em comunidades mais amplas, como o ser humano que quanto mais maduro, mais se integra no seu grupo, neste encontrando condições de aperfeiçoamento, o Estado, ao fazer parte de

\footnotetext{
${ }^{2}$ A interdependência que se estabelece contemporaneamente entre os Estados aponta para um cada vez maior atrelamento entre as idéias de soberania e de cooperação jurídica, econômica e social, o que afeta drasticamente a pretensão à autonomia. Por mais que se argumente no sentido de que esta colaboração só é possível em razão da própria soberania, a qual permitiria a um Estado vincular-se a outro(s) em questões que lhe interessem ou para fazer frente a situações paradigmáticas, o que se observa na prática é a revisão radical dos postulados centrais da mesma (STRECK; MORAIS, 2006, p. 140).
} 
um contexto maior, buscou o desenvolvimento (STELZER, 2000, p.81) e o bem-estar aos seus jurisdicionados.

De tal modo, esse artifício não se trata de algo recente. O movimento integracionista iniciou-se há décadas, na verdade, há séculos. (LUPI, 2001, p.199). Em praticamente todos os continentes, em períodos diferentes da história, a idéia de integração esteve presente. Na época dos impérios, foi utilizada por várias vezes, quase sempre pelo uso do domínio e da força militar, visando restituir o poder e dinamizar a economia. (BEÇAK, 2002, p.15-16). O que mudou recentemente foram o modo, o ímpeto e a velocidade com que as relações internacionais passaram a realizar-se. Sucede que o caráter de união dos Estados não é o mesmo. Antes, quando as pessoas de agrupavam, o faziam com o intuito de obter segurança. Atualmente o processo de integração está ligado às formas de cooperação para um desenvolvimento maior para o seu povo.

Contudo, as Comunidades Européias surgiram como modelo alternativo ao clássico da mera cooperação intergovernamental. Não obstante, a Europa como espaço de união política também não constitui uma idéia nova, fruto da coexistência dos interesses políticos, econômicos e militares atuais. Foi longo o percurso valorativo e cultural que fundou a comunhão de sentido. Nesse caminho encontrou elementos agregadores (como os legados grecoromano e cristão) e elementos de sentido oposto, como os que resultam da constatação de que a Europa é, na sua origem e conseqüência, um caldo de culturas, línguas, tradições e sentimentos nacionais. (GORJÃOHENRIQUES, 2007, p.29-30).

A Europa soube construir, no entanto, ao longo do século XIX, por sobre as fronteiras erguidas no decurso de um milênio e através de freqüentes congressos políticos e conferências técnicas, um espírito de entendimento, de cooperação efetiva e de enriquecimento mútuo (CAMPOS; CAMPOS, 2004, p.26) que proporcionou ao Velho Continente um século de paz e enorme desenvolvimento econômico, técnico e cultural.

Sucede que Roma ofereceu uma série de elementos que transitaram para o patrimônio comum de parte significativa da Europa. Entre eles destacam-se a língua, a paz romana e o elemento cristão, que veio a assumirse como principal elemento agregador e constituinte da tradição européia do continente. Foi nesse período de unidade religiosa e de recepção do direito romano que se assistiu a uma época (séculos XI-XIII) de crescimento agrícola e demográfico, que fez surgir novos e importantes centros de 
comércio e, paralelamente, conduziu à crise da Igreja, que acabou provocando o surgimento dos Estados nacionais ${ }^{3}$, no sentido moderno do termo. (GORJÃO-HENRIQUES, 2007, p.30-31).

Com isso, a Europa passou a apresentar-se como um conjunto de Estados com interesses próprios, em permanente antagonismo. (ALVES, 1992, p.16). Embora apareça já na Idade Média em autores como Beaumanoir e Marino da Caramanico, é indubitável que a noção de soberania como suprema potestas superiorem non recognoscens (poder supremo que não reconhece outro acima de si) remonta ao nascimento dos grandes Estados nacionais europeus e à divisão correlativa, no limiar da Idade Moderna, da idéia de um ordenamento jurídico universal, que a cultura medieval havia herdado da romana. (FERRAJOLI, 2002, p.1-2). Falar de soberania e de seus eventos históricos e teóricos quer dizer, assim, falar dos acontecimentos dessa formação políticojurídica particular que é o Estado nacional moderno.

Somente com o fim do Segundo Grande Conflito é que nasce, nesse compasso, uma real idéia de integração. Ao mesmo tempo em que o caos completo estava instaurado e que os povos remoíam ódios invisíveis entre si, emergia também a consciência da necessidade de uma nova ordem européia. Se, por um lado, a mera idéia de um novo confronto tornava-se inacessível ao espírito europeu, por outro, a globalização econômica avançava e também exigia uma nova postura por parte das nações européias. ${ }^{4}$

O Estado, a propósito disso, apresentava-se demasiado grande para as coisas pequenas e demasiado pequeno para as coisas grandes. Grande demais para a maioria de suas funções administrativas, que passaram a exigir formas de autonomia e de organização que contrastavam com os velhos moldes centralizadores. (FERRAJOLI, 2002, p.50-51). E, pequeno demais, com respeito

\footnotetext{
${ }^{3}$ Independentemente do "nome da coisa" ou do mérito dos argumentos alinhavados a favor de uma tese ou de outra, é importante deixar assentado que o Estado Moderno é uma inovação. A começar pelo fato de que, no feudalismo, o poder é individualizado - encarna-se num homem que concentra na sua pessoa os instrumentos da potência e a justificação da autoridade (poder carismático, na acepção de Weber). Como contraponto, no Estado Moderno, a dominação passa a ser legal-racional, sendo seu tipo mais paro a "dominação burocrática", onde qualquer direito pode ser criado e modificado mediante um estatuto sancionado corretamente quanto à norma; ou seja, obedece-se não à pessoa em virtude de seu direito próprio, mas à regra estatuída, que estabelece ao mesmo tempo a quem e em que medida se deve obedecer (STRECK; MORAIS, 2006, p. 41).

${ }^{4}$ É nesse sentido que se apresenta uma distinção entre o que se deve compreender por governança intergovernamental e governança supranacional. Por governança intergovernamental têm-se como principais atores os chefes de Estado dos membros que negociam entre si na busca pela implantação de uma política comum. Por outro lado, governança supranacional é aquela centralizada em estruturas governamentais, ou seja, instituições próprias com poder de influenciar o comportamento de seus membros (STELZER, 2000, p.21).
} 
às funções de governo e de tutela que se tornavam necessárias devido aos processos de internacionalização da economia e às interdependências cada vez mais sólidas.

Através da decisão dos congressistas no Congresso de Haia de criar um Comitê para a Europa Unida, sob cuja égide a maior parte dos movimentos próeuropeus acabaria por se federar no seio do Movimento Europeu, a edificação da Europa iria desenvolver-se em duas frentes: a de cooperação - no pleno respeito da soberania dos estados europeus; e da integração - que acabaria por se impor - tendente à instituição entre os Estados participantes de um embrião de laço federal vocacionado para congregar um dia, no quadro dos Estados Unidos da Europa, um grupo de países que ao longo dos séculos se haviam periodicamente enfrentado nos campos de batalha. (CAMPOS; CAMPOS, 2004, p.39).

Nesse sentido, importa frisar que a integração comunitária não foi um fenômeno social, eis que começou de cima para baixo e não o inverso. As comunidades européias não nasceram espontaneamente. Constituíram o resultado da persecução de um certo grau de aproximação econômica, política e social entre os Estados da Europa Ocidental (ALVES, 1992, p.16) que, paulatina e progressivamente, foram construindo o projeto comunitário.

Nesse diapasão, um novo conceito de soberania, afastada sua noção tradicional, aponta para a existência de um Estado não isolado, mas incluso numa comunidade. Neste cenário, o Estado-nação ganha novos contornos e os conceitos de soberania e legitimidade adquirem novos significados, uma vez que o Estado perde a capacidade de responder isoladamente aos desafios do sistema internacional. (SASSEN, 2001, p.49).

O fato é que primeiro há a abdicação dos Estados membros de certos poderes que legitimavam a supremacia absoluta do seu ordenamento jurídico (transferência de soberania); em seguida, há a sujeição dos países integrantes (no âmbito da competência transferida) ao novo comando legal comunitário (poder normativo), mas, sempre levando em consideração, os altos objetivos integracionistas (STELZER, 2000, p.145) (dimensão teleológica de integração).

Desse modo, o ordenamento comunitário funcionaria se não como uma Confederação de Estados ou um Estado Federal - no qual a Constituição Federal se confronta com as constituições dos Estados individuais, que não apenas emana-se de princípios fundamentais e regras de organização políticoadministrativa, mas contém elencos de liberdades e direitos fundamentais talvez até mais amplos daqueles federais - pelo menos como um sistema de instituições 
supra-nacionais, intergovernamentais ou representativo-eletivas, constituindo um novo conjunto de organismos públicos, técnicos, jurisdicionais e burocráticos em atendimento a nova tipologia de governance. $^{5}$

Por isso, o cenário que se afigura no Velho Continente é distinto de qualquer outro verificável no contexto internacional, vez que a ordem jurídica comunitária possui regras próprias, onde os Estados limitaram os seus poderes legislativos soberanos, permitindo a existência de um comando supranacional por cima de suas autoridades. Com efeito, devemos nos afastar das categorias tradicionais do direito clássico, do direito internacional público e do direito interno, uma vez que a ruptura consiste precisamente na introdução de elemento diverso, é conceito que toma de empréstimo dados de todos esses campos do direito já referidos, para ordená-los de modo distinto (STELZER, 2000, p.96), em vista de objetivos específicos.

Tal observação mostra que, reconhecida a aplicabilidade direta ao direito comunitário como um todo, restava necessário estabelecer-se qual a relação entre este e o direito nacional. Em caso de haver normas contraditórias provenientes de cada um deles, ambas diretamente aplicáveis, surgia o problema de estabelecer qual prevaleceria (REIS, 2001, p.189). Esta função foi cumprida pelo Tribunal Europeu, que apesar do silêncio dos tratados, afirmou o primado do direito comunitário. O caso Costa/ENEL deu origem, nesse sentido, ao desenvolvimento dessa teoria geral das relações entre o direito comunitário e o direito interno.

\section{A CONSTRUÇÃO DO PRIMADO DO DIREITO COMUNITÁRIO E A MUDANÇA DE PARADIGMA}

A questão objeto do Processo $\mathrm{n}^{\circ}$ 6/64 (Costa c. E.N.E.L.), que teve o acórdão publicado em 03 de junho de 1964, dizia respeito à aplicação da lei italiana de nacionalização da energia elétrica, denunciada como incompatível

\footnotetext{
${ }^{5}$ Essa nova tipologia conceitual é empregada indiferentemente como uma nova categoria descritiva e analítica mais idônea do que a tradicional expressão government para identificar o governo da sociedade complexa. De fato, a nova forma analítica apresentaria a vantagem de considerar os centros de decisão financeira e monetária (a começar pelos bancos), os organismos supranacionais, as chamadas autoridades administrativas independentes e os lobbies econômicos e sociais (como, por exemplo, os sindicatos de trabalhadores e empregadores) não como agentes externos à forma de governo, mas como parte integrante do sistema político/administrativo em consideração. Assim, fala-se em governance a propósito da União Européia, mas também do governo metropolitano ou regional, dos sistemas administrativos complexos etc., enquanto não parece que até o momento tal conceito tenha permeado entre os especialistas em direito constitucional (AMIRANTE, 2003, p.30).
} 
com o Tratado CE. Proposta a ação na jurisdição italiana, o governo sustentava que o juiz deveria aplicar a lei nacional, posterior à lei que aprovara o tratado CE. O juiz milanês, competente para o julgamento, suscitou o reenvio prejudicial. Ao analisar o presente, a Corte deixou claro que, diferentemente do que sucede com os tratados internacionais ordinários, o Tratado CE instituiu uma ordem jurídica própria, que se impõe às jurisdições nacionais. $\mathrm{O}$ direito resultante do tratado não poderia, assim, em razão da sua natureza específica original, ver-se judiciariamente confrontado com um texto de direito interno, qualquer que este fosse, sem perder seu caráter comunitário e sem que fosse posta em causa a base jurídica da própria Comunidade. (REIS, 2001, p.189-190).

A Corte reconheceu que ao instituírem uma Comunidade de duração ilimitada, dotada de instituições próprias, de personalidade, de capacidade jurídica, de capacidade de representação internacional e, mais especialmente, de poderes reais resultantes de uma limitação de competências ou de uma transferência de atribuições dos Estados para a Comunidade, estes limitaram, ainda que em domínios restritos, os seus direitos soberanos e criaram, assim, um corpo de normas aplicável aos seus nacionais e a si próprios. Afirmou que esta integração, no direito de cada Estado-membro, de disposições provenientes de fonte comunitária e, mais geralmente, os termos e o espírito do Tratado têm por corolário a impossibilidade, para os Estados, de fazerem prevalecer ${ }^{6}$, sobre uma ordem jurídica por eles aceite numa base de reciprocidade, uma medida unilateral posterior que não se lhe pode opor.

As obrigações assumidas no Tratado que instituiu a Comunidade não seriam absolutas, mas apenas eventuais, se pudessem ser postas em causa por posteriores atos legislativos dos signatários. Resulta do conjunto destes elementos que ao direito emergente do Tratado, emanado de uma fonte autônoma, em virtude da sua natureza originária específica, não pode ser oposto um texto interno, qualquer que seja, sem que perca a sua natureza comunitária e sem que sejam postos em causa os fundamentos jurídicos da própria Comunidade. A transferência efetuada pelos Estados, da sua ordem jurídica interna em benefício da ordem jurídica comunitária, dos direitos e obrigações

\footnotetext{
${ }^{6}$ Também sob o enfoque internacionalista, numerosos juristas, reagindo às dificuldades de implementação das normas multilaterais, são acometidos de uma espécie de neo-nacionalismo, que os leva à busca incessante da transposição ao plano internacional das categorias que correspondem ao Estado-nação. O inevitável fracasso da transposição conduz, por outra via, ao mesmo recalque. Ora, a intensa permeabilidade do direito internacional a dados extra-positivos explica que seu processo de interpretação jamais se tenha formalizado nos moldes das disciplinas internas, e que, não raro, ele se encontrasse totalmente apartado dos dogmas legalistas (VENTURA, 2008, p.235).
} 
correspondentes às disposições do Tratado, implica, pois, uma limitação definitiva dos seus direitos soberanos, sobre a qual não pode prevalecer um ato unilateral ulterior incompatível com o conceito de Comunidade.

Com isso, concluiu que o artigo $53 .^{\circ}$ e o artigo $37 .^{\circ}, \mathrm{n} .{ }^{\circ} 2$ tratavam-se de normas comunitária susceptíveis de atribuir aos particulares direitos que os órgãos jurisdicionais nacionais deveriam salvaguardar. As suas disposições proibiam qualquer nova medida que tivesse por finalidade submeter o estabelecimento dos nacionais dos outros Estados-membros a uma regulamentação mais rigorosa que a aplicável aos seus nacionais, independentemente do regime jurídico das empresas, quanto às condições de abastecimento e de comercialização, através de monopólios ou organismos que devem, por um lado, ter por objeto transações de um produto comercial susceptível de concorrência e de trocas comerciais entre os Estados-membros e, por outro, desempenhar um papel efetivo nessas trocas.

Como se vê, o primado do direito se baseia no fato de que seu fundamento não está no direito nacional, e sim na soberania da qual os Estados abriram mão em favor da Comunidade. Segundo a argumentação da Corte, a força executiva do direito comunitário não poderia, com efeito, variar de um Estado para outro ao sabor das legislações internas ulteriores, sem pôr em perigo a realização das finalidades dos tratados. Essa linha de decisão foi confirmada por diversos acórdãos que se seguiram, incluindo, na década de 70, o caso Simmenthal Processo 106/77 - Acórdão do Tribunal de Justiça publicado em 9 de Março de 1978. (REIS, 2001, p.190).

O presente tratava-se de pedido dirigido ao Tribunal de Justiça destinado a obter, no litígio pendente neste órgão jurisdicional nacional entre Administração das Finanças do Estado e Sociedade Anônima Simmenthal, uma decisão a título prejudicial ${ }^{7}$ sobre as conseqüências da aplicabilidade direta do direito comunitário em caso de conflito com disposições eventualmente contrárias de direito nacional.

\footnotetext{
${ }^{7} \mathrm{O}$ funcionamento da União Européia está sujeito a um controle jurisdicional peculiar. Como os juízes nacionais são também juízes do direito comunitário, a coerência e a homogeneidade entre os julgados dos juízes dos vários países-membros é ditada pela Corte de Justiça, dentro do que se pode chamar de cooperação, sem hierarquia, entre juízes nacionais e a aludida Corte. Essa cooperação se opera por meio de um procedimento de renvoi préjudiciel, dos primeiros à segunda, em busca de uma apreciação de validade ou de interpretação da norma comunitária. Em assim sendo, pode-se conceituar o reenvio prejudicial como sendo um mecanismo de cooperação judiciária por meio do qual se busca a certeza jurídica da norma comunitária, primária ou derivada, quer quanto à sua correta interpretação, quer quanto à sua validade. Não há apreciação quanto à matéria de fato, a qual fica reservada às jurisdições nacionais (PAULILO, 2000, p.129).
} 
A Corte iniciou ressaltando que a aplicabilidade direta, assim perspectivada, implica que as normas de direito comunitário produzam a plenitude dos seus efeitos, de modo uniforme em todos os Estados-membros, a partir da sua entrada em vigor e durante todo o período da respectiva vigência. Na seqüência, pontuou que por força do princípio do primado do direito comunitário, as disposições do Tratado e os atos das instituições diretamente aplicáveis têm por efeito, nas suas relações com o direito interno dos Estados-membros, não apenas tornar inaplicável de pleno direito, desde o momento da sua entrada em vigor, qualquer norma de direito interno que lhes seja contrária, mas também impedir a formação válida de novos atos legislativos nacionais, na medida em que seriam incompatíveis com normas do direito comunitário.

Com efeito, concluiu que o reconhecimento de qualquer forma de eficácia jurídica a atos legislativos nacionais que invadem o domínio no qual se exerce o poder legislativo da Comunidade, ou que por qualquer forma se mostrem incompatíveis com disposições do direito comunitário, implicaria a negação do caráter efetivo dos compromissos assumidos pelos Estadosmembros, por força do Tratado, de modo incondicional e irrevogável, contribuindo assim para pôr em causa os próprios fundamentos da Comunidade. ${ }^{8}$ Decorre disso que qualquer juiz nacional tem o dever de, no âmbito das suas competências, aplicar integralmente o direito comunitário e proteger os direitos que este confere aos particulares, considerando inaplicável qualquer disposição eventualmente contrária de direito interno, quer seja esta anterior ou posterior à norma comunitária.

Assim, o juiz nacional responsável, no âmbito das suas competências, pela aplicação de disposições de direito comunitário, tem obrigação de assegurar o pleno efeito de tais normas, decidindo, por autoridade própria, se necessário for, pela não aplicação de qualquer norma de direito interno que as contrarie, ainda que tal norma seja posterior, sem que tenha de solicitar ou esperar a prévia eliminação da referida norma por via legislativa ou por qualquer outro processo constitucional.

\footnotetext{
${ }^{8}$ Enquanto disciplina jurídica nova, o direito comunitário também possui um método que lhe é próprio, empregando instrumentos gnoseológicos e hermenêuticos especiais, sem prescindir daqueles do direito interno e do direito internacional, em face de seu hibridismo, privilegiando a interpretação teleológica ou finalística. Com efeito, dada a diversidade lingüística em que os tratados instituidores da União Européia são vazados, a interpretação literal ou gramatical fica praticamente impossibilitada, emergindo a busca dos fins da integração como o método mais recomendado para se extrair o exato sentido das normas comunitárias (LEWANDOWSKI, 2000, p.185).
} 
Desse modo, se houver conflito entre as duas ordens jurídicas, ainda que de cunho constitucional, a regra interna cederá perante a norma da UE, situação que a história do direito ainda não tinha registrado. Acima da legislação oriunda do Estado, nunca se havia verificado qualquer tipo de ingerência que pudesse elevar-se por sobre a sua autoridade, eis que tudo que se constatava no palco externo era fulcrado na cooperação entre os países e no respeito à soberania nacional. (STELZER, 2000, p.144).

Tanto é assim que no processo 11/70, cujo acórdão fora publicado em 17 de Dezembro de 1970 e teve por objeto um pedido dirigido ao Tribunal de Justiça ${ }^{9}$ pelo Verwaltungsgericht (tribunal administrativo) Frankfurt am Main, destinado a obter, no processo pendente neste órgão jurisdicional entre Internationale Handelsgesellschaft $\mathrm{mbH}$ e Einfuhr- und Vorratsstelle für Getreide und Futtermittel, uma decisão a título prejudicial sobre a validade de dados artigos de Regulamentos, restou assentado que o recurso às regras ou noções jurídicas do direito nacional, para a apreciação da validade dos atos adotados pelas instituições da Comunidade, teria por efeito pôr em causa a unidade e a eficácia do direito comunitário. A validade desses atos não pode ser apreciada senão em função do direito comunitário. Com efeito, ao direito emergente do Tratado, emanado de uma fonte autônoma, não podem, em virtude da sua natureza, ser opostas em juízo regras de direito nacional, quaisquer que sejam, sob pena de perder o seu caráter comunitário e de ser posta em causa a base jurídica da própria Comunidade; portanto, a invocação de violações, quer aos direitos fundamentais, tais como estes são enunciados na Constituição de um Estado-membro, quer aos princípios da estrutura constitucional nacional, não pode afetar a validade de um ato da Comunidade ou o seu efeito no território desse Estado.

O primado do direito comunitário representa, assim, a prevalência hierárquica do direito comunitário originário ou derivado sobre qualquer regra de direito nacional contrária, quer seja anterior ou posterior, de natureza constitucional ou infraconstitucional. O primado do direito comunitário impõese, indo mais além, quer se as suas normas sejam ou não diretamente aplicáveis, produzam ou não efeito direto. O fato é que a aplicabilidade direta seria letra

\footnotetext{
${ }^{9}$ Esse verdadeiro complexo jurídico vem assegurando a unidade européia, de modo a superar as marcantes diferenças regionais que se apresentariam nas diferentes jurisdições, bem como, a evitar a dispersão na praticização do comando legal comunitário relativamente ao caso concreto, que se daria no caso da improvisação jurisdicional que ocorreria se se instituísse uma unidade de julgamento específico de cada caso (BENETI, 2000, p.219).
} 
morta se os Estados-membros pudessem se subtrair à aplicação do direito comunitário por uma simples norma nacional, qualquer que fosse a sua hierarquia. Pontualmente, o direito comunitário deve ser uniformemente interpretado e aplicado, sob pena de os mesmos cidadãos da Comunidade terem direitos e obrigações diferentes conforme o país em que se encontrem. Deve ser obrigatório, em igual medida, em todos os países membros. (ALVES, 1992, p.310-311). A natureza comunitária do direito perder-se-ia se qualquer Estado pudesse se subtrair aos seus comandos, paralisando os seus efeitos. Por oportuno, a natureza da comunidade repousa na limitação dos poderes soberanos dos Estados-membros. Se assim é, os Estados-membros têm de se sujeitar à ordem jurídica por eles criada.

Ocorre que, por vezes, é estabelecida a competência exclusiva da Comunidade em certas áreas, afastando toda e qualquer interferência estatal. Em outras, permite-se a atuação comunitária sem excluir as competências nacionais, mantendo-se o espectro de poderes estatais. Nestes casos, cabe às instituições comunitárias o papel de harmonizar as ações nacionais ou agir em coordenação com elas. Há ainda outra hipótese de relacionamento entre o direito comunitário e o direito nacional. São os casos de competência concorrente, em que ambos co-existem, cumprindo cada um sua função própria. Há, nesse caso, uma relação de coordenação entre ambos. As regras comunitárias são válidas em todos os Estados-membros, que devem respeitá-las e fazê-las respeitar, sem, no entanto, abdicar de produzir outras regras que entendam convenientes. (REIS, 2001, p.178-180).

Em outras palavras, entre a ordem jurídica nacional dos Estados-membros e a ordem jurídica comunitária pode haver relações de substituição, de harmonização, de coordenação e de coexistência de legislações. ${ }^{10}$ Sucede que no direito comunitário vigora a tese monista. $\mathrm{O}$ direito comunitário integra-se na ordem jurídica interna dos Estados-membros sem qualquer cláusula de recepção interna; como direito comunitário, com todas as suas características, princípios; e não como direito interno. Todas as autoridades nacionais tem o dever, assim, de respeitar e aplicar sua essência. (ALVES, 1992, p.292-293). Doutra forma, perderia seu alcance.

\footnotetext{
${ }^{10}$ Todas essas observações demonstram que os princípios do primado da ordem comunitária relativamente aos direitos dos Estados-membros e o efeito direto de toda uma série de disposições aplicáveis aos nacionais e aos próprios Estados, representam uma verdadeira revolução no Direito, com repercussão direta sobre seu ensino e aprendizagem. É tempo, de tal sorte, de o estudo do Direito ser repensado e procurar antecipar-se, em lugar de apenas trabalhar com o passado (NALINI, 2000, p.257-60).
} 
Nesses termos, firmou-se que as normas comunitárias têm aplicabilidade direta, ou seja, tem validade e eficácia nos ordenamentos internos de cada Estado da União, sem necessidade de transformação por meio de ato específico. O que se seguiu a isso foi a questão sobre a derrogação do direito do Estadomembro que fosse contrário à norma comunitária ou a possibilidade de adoção futura que contrariasse essa norma (CANOTILHO, 2003, p.825), surgindo, então, a primazia do direito comunitário como possível solução para o conflito.

Entretanto, o presente não encerrou o problema, eis que, com isso, emergiarm novos questionamentos: na era da governance, a dupla Estado Nacional-Constituição perdeu definitivamente e irreversivelmente seu significado, sendo relegada ao plano de instrumento de análise histórico-institucional ou está na hora de apartar o conceito histórico de Constituição à peculiaridade da situação européia, que certamente coloca-se num plano distinto daquele das peculiaridades nacionais? (AMIRANTE, 2003, p.37-38).

\section{O ESTADO EM REDE EUROPEU}

A Grande Europa, a União Européia e os seus Estados-membros encontram-se no interior de um processo de relativa ebulição constitucional, apontando como horizonte um novo constitucionalismo. (PIRES, 1997, p.2021).

Isso resta evidenciado pela dupla face deste novo Estado (constitucional europeu) que toma forma, enquanto europeização das Constituições nacionais, por um lado, e formação de um nível mais alto e comum de direito constitucional. ${ }^{11}$

A questão constitucional no debate europeu articulou-se, assim, em três aspectos estritamente ligados entre si. Em primeiro lugar, a chamada questão interna, que diz respeito ao estado de saúde das Constituições, à manutenção da Lei Fundamental e à exigência de revisão constitucional no contexto comunitário. Em segundo lugar, a questão da chamada Constituição Européia que equivale a responder ao questionamento: existe uma Constituição Européia?

\footnotetext{
${ }^{11}$ Em sentido material, uma Constituição européia já existe há muito, reconduzindo-se aos Tratados institutivos e respectivas atualizações. Não obstante, decidiu-se avançar para uma Constituição formal, isto é, para um tratado que instituísse uma Constituição para a Europa. O mesmo, assinado em outubro de 2004, foi rejeitado pelos referendos francês e holandês em 2005. A Europa mergulhou, então, numa dolorosa crise constitucional de dois anos que só seria resolvida em dezembro de 2007, com a assinatura do Tratado de Lisboa. Nesse enfoque, talvez fosse inevitável tal desfecho: a União Européia, enquanto modelo pós-moderno que é, não se compadece com as fórmulas da modernidade - como seja a idéia de Constituição formal, ainda muito atrelada àquela de Estado soberano - tendo de encontrar suas próprias soluções (SILVEIRA, 2008, p. 48-49).
} 
É auspiciável uma Constituição Europeia que ultrapasse a coordenação ou os pequenos retoques? Por fim, qual o futuro da Constituição nacional? (AMIRANTE, 2003, p.211-212). Ela perde validade e efetividade frente às normas e regras do ordenamento comunitário, entendido como um ordenamento em contínua evolução política e institucional?

O fato é que Maastricht provocara a alteração de oito das doze constituições dos Estados então membros da Comunidade. Isso acordava para uma necessidade de recíproco reconhecimento, abertura e coordenação entre os dois níveis constitucionais. Nesse sentido, o próprio TJ aclarou sem rodeios (Parecer 1/91 sobre o Tratado do Porto que deu origem ao Espaço Econômico Europeu) que embora o Tratado da CEE tenha sido concluído sob a forma de um acordo internacional, não é por isso que deixa de ser a carta constitucional de uma Comunidade de direito. (PIRES, 1997, p.46-51).

Essa proposta subverteu a lógica da unidade, produzindo diferentes esferas compartilhadas de poder. A experiência européia dá margem, assim, ao Estado em rede proposto por Castells, que se caracteriza por partilhar a autoridade (ou seja, a capacidade institucional de impor uma decisão) ao longo de uma rede de instituições. Nos processos de tomada de decisão, o Estado-nação se relaciona com instituições supranacionais de diferentes tipos e em diferentes âmbitos, assim como, com instituições locais e regionais, e até mesmo com ONGs. O que sugere essa teoria repousa justamente no conceito de rede que, por definição, tem nós, não centro. Nós que podem ser de tamanhos diferentes e estar ligados por relações assimétricas. (FLOH, 2005, p.87-88). Dessa forma, o Estado em rede, antes de propor um novo paradigma para substituir o Estado-nação, reconhece a existência de ordens jurídicas, ou formas de poder, paralelas e complementares, não excludentes como supõe a realidade atual.

Não existe, pois, o "fim da história" quanto à idéia do constitucionalismo. Porém, a maior parte das nervuras dogmáticas deste direito pertence a um mundo que já não é nosso. Temos, por isso, que procurar o novo mundo. (CANOTILHO, 2006, p.37). As redes constituem a nova morfologia social de nossas sociedades, e a difusão da lógica de redes modifica de forma substancial a operação e os resultados dos processos produtivos e de experiência, poder e cultura. (CASTELLS, 1999, p.497).

Observa-se uma clara separação de competências: aquelas outorgadas para o ente supranacional, ou o nó superior do Estado em rede, e aquelas mantidas para o nó intermediário, o Estado-nação, que, por sua vez, tem condições e, efetivamente o faz, de partilhar as competências que lhe são próprias entre os 
órgãos ou instâncias sub-nacionais, ou regionais. Veja-se que nesta divisão de poder não há nenhuma instância autônoma de poder e/ou competências, partilhando-se as responsabilidades, pois, de maneira setorial. Até mesmo nas competências outorgadas exclusivamente para a UE, observa-se a interferência dos Estados-membros, uma vez que sua participação no âmbito do Conselho da UE, nas formas previstas e estabelecidas na Constituição, permite sua constante e presente atuação no processo decisório (FLOH, 2005, p.94) e na construção da vontade da UE.

O fato é que, este constitucionalismo, ainda que produzindo uma revisão quase "total", trata-se de um prolongamento e não, como se poderia olvidar, de uma ruptura. A supremacia das normas comunitárias, dir-se-ia, ela própria, é subsidiária, limitada às esferas das competências que lhe são atribuídas. Deve ser interpretada, assim, como diferenciação de tarefas, de acordo com o princípio da subsidiariedade, entre um círculo mais amplo e outro mais restrito, os quais se situam, porém, em níveis diferentes, não necessariamente hierarquizados. (PIRES, 1997, p.106).

A subsidiariedade acaba sendo proposta, portanto, como uma das vias de atuação do princípio democrático, tanto no âmbito comunitário como na garantia de respeito às competências e aos poderes soberanos dos Estadosmembros e das articulações regionais, inclusive com o objetivo de tutelar os direitos fundamentais dos cidadãos europeus (AMIRANTE, 2003, p.189), assegurando a atuação e a regulamentação dos direitos o mais próximo possível dos seus titulares.

Ocorre que nos domínios que não sejam das suas atribuições exclusivas, a Comunidade intervém apenas de acordo com o princípio da subsidiaridade ${ }^{12}$, se e na medida em que os objetivos da ação encarada não possam ser suficientemente realizados pelos Estados-membros, e possam, pois, devido à dimensão ou aos efeitos da ação prevista, ser melhor alcançados a nível comunitário. Este princípio é prudencialmente completado pelo princípio de proporcionalidade, que estabelece que a ação da comunidade não deve exceder o necessário para atingir os objetivos do tratado. Assim, atrás do princípio da subsidiariedade está: (1) a idéia de freio e balanço relativamente a um crescente

\footnotetext{
${ }^{12}$ A grande maioria dos poderes comunitários encontra-se compartilhada entre os Estados-membros e a Comunidade Européia, fazendo com que a competência exclusiva seja aplicada a raras hipóteses. A precisa divisão de competências entre a Comunidade Européia e os Estados-membros varia entre as específicas áreas de atuação, tendendo, ademais, a redação a ser imprecisa, circunstâncias essas que justificam a relevância do presente princípio (JANKOV, 2005, p.214).
} 
centralismo europeu; (2) a idéia de regionalizar mais fortemente os processos de decisão comunitários; (3) a idéia de encontrar decisões o mais possível próximas dos cidadãos (democracia da proximidade), não lhe sendo também alheia a idéia de pluralismo e diferenças culturais e históricas dos Estadosmembros, bem como, das respectivas dimensões territoriais (CANOTILHO, 2003, p.368).

Em realidade, a partir da proposta de um Estado em rede europeu, refletido por meio de uma comunidade política regional institucionalizada, observase o rompimento com o monopólio do poder pelo Estado-nação, ou a destruição do conceito clássico de soberania (FLOH, 2005, p.95-96), transformando-o em mais um ente político-administrativo, incluído nas cada vez mais complexas relações sociais ${ }^{13}$.

Nesses termos, as duas esferas, comunitária e nacional, são autônomas e multinível, podendo ser olhadas conciliadoramente, através da chamada jurisprudência dos sistemas. $\mathrm{O}$ fato é que pode haver zonas de sobreposição e concorrência em áreas menos definidas e ainda mal arbitradas pelo princípio da subsidiariedade e pelos critérios de atribuição de competências, mas isso não implica que as esferas sejam, em princípio, contraditórias ou competitivas. (PIRES, 1997, p.107-108). Sucede que, se a Constituição européia fala para baixo, as Constituições nacionais falam para cima, como se a Constituição européia se nacionalizasse enquanto a Constituição nacional se europeíza.

O objeto de estudo da teoria da interconstitucionalidade é, assim, justamente a rede. A teoria da interconstitucionalidade estuda, pois, a concorrência, convergência, justaposição e conflito de várias Constituições e de vários poderes constituintes no mesmo espaço político. Postula a articulação entre Constituições, a afirmação de poderes constituintes com fontes e legitimidades diversas, e a compreensão da fenomenologia jurídica e política amiga do pluralismo de ordenamentos e de normatividades. No fundo, trata-se de uma forma específica de interorganização política e social. (CANOTILHO, 2003, p.1425).

${ }^{13}$ Com insistência nesse argumento, Robert Keohane e Joseph Nye desenvolveram o conceito de interdependência complexa, que apresenta uma multiplicidade de problemáticas de análise que abordam, entre outros temas, a economia, o meio-ambiente, a cultura, os direitos humanos e o terrorismo. Em cada uma dessas áreas, existe mais de uma dimensão com padrões específicos de influência, como consumo, desenvolvimento, autodeterminação, costumes, etc. A definição de interesse de Estado, a influência dos autores dentro dos próprios Estados e a maneira como os Estados interagem com esses novos atores através de uma teia de relações onde somente algumas passam pela via formal, tratandose também a via de informalidade como um campo de propagação de influência, estabelece um pensar inovador e plural das relações internacionais, que conseqüentemente afetar a eficácia e instrumentalidade do constitucionalismo nacional e internacional (SALDANHA, 2005, p.58). 
Como autodescrição das identidades nacionais, as várias Constituições dos vários países reentram em formas organizativas superiores. Os textos constitucionais dos Estados conservam a memória social e identidade política. Precisamente por isso, os textos constitucionais inseridos na rede interconstitucional assumem-se sempre como autorreferência. A insistência nesse caráter autodescritivo e autorreferente dos textos constitucionais estaduais aponta para a manutenção do valor e função das Constituições estaduais. Estas Constituições desceram do castelo para a rede, mas não perderam identidade em virtude de agora estarem em interligação umas com outras. A rede formada por normas constitucionais nacionais e por normas européias faz abrir os castelos e relativizar outros princípios estruturantes clássicos dos ordenamentos, como os princípios da hierarquia e da competência (CANOTILHO, 2006, p.269), mas não dissolve nas suas malhas o tipo de Estado constitucional.

Sucede que o ordenamento estadual abre-se a fontes de direito supranacionais, alterando-se radicalmente o monopólio estadual de criação do direito. Não obstante, os textos constitucionais que mantêm a autorreferência dos sistemas nacionais recentram na rede para, desde logo, assegurarem a implantação de respeito às identidades nacionais. Mas não só: estar em rede implica também a possibilidade de observação das outras descrições nacionais e supranacionais. ${ }^{14}$ Os processos de troca entre as várias Constituições com a sua história própria e tradições culturais produzem uma cultura constitucional reconduzível a idéias, valores, ações de indivíduos e de grupos. A interculturalidade começa por ser uma partilha comunicativa destes valores e idéias concretamente traduzidas em fórmulas não jurídicas, para, mais tarde, possibilitar uma tendencial normativização. (CANOTILHO, 2003, p.1427-1428).

A interconstitucionalidade sugere intersemioticidade, no sentido de que ela não dispensa a investigação e descoberta de um conjunto de regras respeitantes à produção e interpretação dos textos constitucionais e dos respectivos discursos e práticas sociais com eles relacionados. Neste sentido se pode afirmar recentemente que as Constituições nacionais são dimensões

\footnotetext{
${ }^{14}$ A autopoiese chama-nos precisamente a atenção para a fraqueza de um voluntarismo excessivo. Os sistemas resistem a modificações artificialmente impostas. A auto-organização não dispensa um diálogo, uma conversação, uma conexão interativa entre os vários sistemas sociais. Significa isso que as normas constitucionais devem revelar-se aptas a conseguir uma articulação das preferências e interesses públicos dos produtores de normas e as preferências e interesses dos destinatários dessas (CANOTILHO, 2003, p.1452).
} 
relevantes de uma hermenêutica jurídica européia. Depois de terem desempenhado e continuarem a desempenhar a função primordial de cartas vivas da identidade nacional, passaram a contribuir, na qualidade de Constituições parciais de espaços comunitários, para a sedimentação e revelação de identidades culturais pluralmente inclusivas. Nesta perspectiva, o direito constitucional europeu não pode (nem deve) ser um direito construído contra as Constituições nacionais, antes deve descrever-se como um direito materialmente informado pelos princípios estruturante dos Estados de Direito Democrático-Constitucionais (CANOTILHO, 2006, p.277-278) que, ao fim e ao cabo, continuam a ser estruturas políticas profundas da União Européia.

O fato é que a ciência evolui a partir do conflito de teorias e paradigmas. Um paradigma é substituído quando uma nova maneira dominante de pensar os problemas, não resolvidos pelo paradigma vigente, e um novo método para solucioná-los, superam os outros ${ }^{15}$. Este processo também ocorre na "Ciência" do Direito. Quando passa a existir uma confluência de idéias sobre os conceitos e os problemas a serem abordados pelo Direito, bem como a melhor forma de lidar com os mesmos, pode-se dizer que houve a consolidação de um paradigma jurídico. Freqüentemente, diferentes paradigmas jurídicos colidirão e, então, um deles tornar-se-á o dominante; pequenas mudanças e ajustes aperfeiçoarão o paradigma. Quando as respostas para os problemas surgidos não são encontradas dentro do paradigma vigente, paradigmas alternativos surgirão e desafiarão os paradigmas predominantes. (TIMM, 2010, p.203).

Isso é o que se sucede no presente. Tende-se a falar cada vez menos de governo e cada vez mais de governação, um conceito mais amplo do que o de governo. Está em voga a visão da governação em múltiplos níveis, a multi level governance, em cujo âmbito se move toda uma diversidade de atores, e onde governos nacionais passam a ser apenas uma das figuras (CUNHA, 2006, p.219) que atuam no novo contexto hipercomplexo das sociedades do nosso tempo.

O Estado não é o único centro produtor de normatividade. Hoje existem cada vez mais espaços locais de poder onde existem comportamentos obrigatórios, onde existem regras para serem cumpridas, critérios de controle temporal das expectativas normativas da sociedade, que não derivam do Estado.

\footnotetext{
${ }^{15}$ No novo paradigma do direito em rede, com sua interatividade generalidade, ainda há uma gramática por descobrir. Ora, perderam o sentido, portanto, as velhas oposições fora-dentro, nacional-internacional, nós-outros. O direito oficial do Estado centralizado e suas aspirações de abstração, generalidade e universalidade desatualizam-se diante do local, do plural e do subversivo (VENTURA, 2008, p.227-234).
} 
E são extremamente variados: movimentos sociais, sindicatos, ONG's e Comunidades, que têm regras próprias para a tomada de decisões para grupos de pessoas que as seguem. Assim, são outras regras de Direito que estão surgindo. De certa maneira, sempre existiram, mas estão surgindo sob nossa observação. (ROCHA, 2008, p.177).

\section{CONSIDERAÇÕES FINAIS}

Como restou evidenciado, o cenário que se afigura no Velho Continente é distinto de qualquer outro verificável no contexto internacional. A ordem jurídica comunitária desenvolveu-se de tal modo, utilizando as categorias tradicionais do direito clássico, do direito internacional público e do direito interno, que acabou por criar suas próprias regras, tomando empréstimo de dados de todos esses campos do direito e ordenando-os de modo distinto. A erosão do monopólio estatal, não obstante, é simplesmente um ponto dentro de um complexo sistema de modificações das relações de poder, tendo em vista as mutações ocasionadas, paralelamente, nos conceitos de soberania e Constituição.

A construção jurisprudencial do primado do Direito Comunitário enquanto exigência existencial demonstra, senão, isso, através da instauração de situação nunca antes vivenciada pelo direito. Sob a perspectiva de que a aplicabilidade direta do direito comunitário seria letra morta se os Estadosmembros se pudessem subtrair a sua aplicação por uma norma nacional, devendo o direito comunitário ser uniformemente interpretado e aplicado, sob pena de os mesmos cidadãos da Comunidade possuírem direitos e obrigações diferentes conforme o país em que se encontrem, é posta em causa a tradicional concepção hierárquica do Direito, em que as normas constitucionais ocupam o topo das fontes, critério de legitimidade e validade das demais.

Com efeito, questionamentos acerca da perda de significado da dupla Estado Nacional-Constituição começaram a borbulhar. Nesse contexto, o presente trabalho buscou demonstrar que a concepção de Constituição deve ser refletida a partir da peculiaridade da situação européia e mundial atual, que certamente coloca-se num plano distinto daquela nacional. Estado e Constituição na modernidade não estão, pois, em vias de eliminação, mas redefinição. Através do compartilhamento de autoridade, articulam-se numa rede com instituições supranacionais de tipos e âmbitos diferentes, com 
instituições locais e regionais e com organizações não-governamentais. O aparato burocrático do Estado não mais constitui, nesse sentido, o único caminho de interação.

A proposta de paradigma a ser estabelecida é, nesses termos, o Estado em rede, não como substituto do Estado-nação, mas e, na medida, em que reconhece a existência de ordens jurídicas, ou formas de poder, paralelas e complementares, não excludentes como supõe a realidade atual. A teoria da interconstitucionalidade, surge, nesse contexto, postulando a articulação entre Constituições, a afirmação de poderes constituintes com fontes e legitimidades diversas, e a compreensão da fenomenologia jurídica e política amiga do pluralismo de ordenamentos e de normatividades.

\section{REFERÊNCIAS}

ALVES, Jorge de Jesus Ferreira. Lições de direito comunitário. 2.ed. Coimbra: Coimbra, 1992.

\section{AMIRANTE, Carlo. Uniões supranacionais e reorganização} constitucional do Estado. São Leopoldo: UNISINOS, 2003.

BEÇAK, Peggy. Mercosul: uma experiência de integração regional. São Paulo: Contexto, 2002.

BENETI, Sidnei Agostinho. Processo civil supranacional, União Européia e Mercosul. In: LEWANDOWSKI, Enrique Ricardo (Org.). Direito comunitário e jurisdição supranacional. São Paulo: Juarez de Oliveira, 2000 .

CAMPOS, João Mota de; CAMPOS, João Luiz Mota de. Manual de Direito comunitário. 4. ed. Lisboa: Fundação Calouste Gulbenkian, 2004.

CANOTILHO, J. J. Gomes. “Brancosos” e interconstitucionalidade: itinerários dos discursos sobre a historicidade constitucional. Coimbra: Almedina, 2006.

CANOTILHO, J. J. Gomes. Direito constitucional e teoria da constituição. 7. ed. Coimbra: Almedina, 2003. 
CASTELLS, Manuel. A Era da informação: economia, sociedade e cultura. A Sociedade em Rede. 5. ed. São Paulo: Paz e Terra, 1999. v.1.

CUNHA, Paulo de Pitta e. A Constituição Européia: uma perspectiva crítica. Curitiba: Juruá, 2006.

FERRAJOLI, Luigi. A soberania no mundo moderno: nascimento e crise do estado nacional. São Paulo: Martins Fontes, 2002.

FLOH, Fábio. Estado em Rede Europeu, Neo-Regionalismo e Constituição para a Europa. In: GOMES, Eduardo Biacchi; REIS, Tarcísio Hardman (Coord.). Direito Constitucional Europeu: rumos da construção. Curitiba: Juruá, 2005.

GORJÃO-HENRIQUES, Miguel. Direito comunitário: sumários desenvolvidos. 4. ed. Coimbra: Almedina, 2007.

JANKOV, Fernanda F. Fernandez. A Delimitação das Competências Comunitárias no Constitucionalismo Europeu. In: GOMES, Eduardo Biacchi; REIS, Tarcísio Hardman (Coord.). Direito Constitucional Europeu: rumos da construção. Curitiba: Juruá, 2005.

LEWANDOWSKI, Enrique Ricardo. Direito comunitário e soberania: algumas reflexões. In: LEWANDOWSKI, Enrique Ricardo (Org.). Direito Comunitário e Jurisdição Supranacional. São Paulo: Juarez de Oliveira, 2000 .

LUPI, André Lipp Pinto Basto. Soberania, OMC e Mercosul. São Paulo: Aduaneiras, 2001.

NALINI, José Renato. A Integração das Comunidades e a Formação do Operador do Direito. In: LEWANDOWSKI, Enrique Ricardo (Org.).

Direito Comunitário e Jurisdição Supranacional. São Paulo: Juarez de Oliveira, 2000.

PAULILO, Antonio José Silveira. O Renvoi Préjudiciel. In: LEWANDOWSKI, Enrique Ricardo (Org.). Direito Comunitário e Jurisdição Supranacional. São Paulo: Juarez de Oliveira, 2000. 
PIRES, Francisco Lucas. Introdução ao Direito Constitucional

Europeu: seu sentido, problemas e limites. Coimbra: Almedina, 1997.

REIS, Márcio Monteiro. Mercosul, União Européia e Constituição: a integração dos estados e os ordenamentos jurídicos nacionais. Rio de Janeiro: Renovar, 2001.

ROCHA, Leonel Severo. Observações sobre autopoiese, normativismo e pluralismo jurídico. In: MORAIS, José Luis Bolzan de; STRECK, Lenio Luiz (Org.). Constituição, Sistemas Sociais e Hermenêutica. São Leopoldo: UNISINOS, 2008.

SALDANHA, Eduardo. O Constitucionalismo Europeu e o Direito Internacional Público: onde está o poder? In: GOMES, Eduardo Biacchi; REIS, Tarcísio Hardman (Coord.). Direito Constitucional Europeu: rumos da construção. Curitiba: Juruá, 2005.

SASSEN, Saskia. Perdiendo el control? La soberania en la era de la globalización. Barcelona: Edicions Bellaterra, 2001.

SILVEIRA, Alessandra. União de direito e ordem jurídica da União Européia. Revista Eletrônica Direito e Política, Itajaí, v.3, n.3, 3ํa․ 2008.

STELZER, Joana. União Européia e Supranacionalidade: desafio ou realidade? Curitiba: Juruá, 2000.

STRECK, Lenio Luiz; MORAIS, José Luiz Bolzan de. Ciência Política e Teoria do Estado. 5. ed. Porto Alegre: Livraria do Advogado, 2006.

TIMM, Luciano Benetti. A matriz da análise econômica do direito para além do "eficientismo". In: CALLEGARI, André Luís; STRECK, Lenio Luiz; ROCHA, Leonel Severo (Org.). Constituição, sistemas sociais e hermenêutica. São Leopoldo: UNISINOS, 2010. 
VENTURA, Deisy. Hiato da transnacionalização na nova gramática do direito em rede: um esboço de conjugação entre estatalismo e cosmopolitismo. In: MORAIS, José Luis Bolzan de; STRECK, Lenio Luiz (Org.). Constituição, Sistemas Sociais e Hermenêutica. São Leopoldo: UNISINOS, 2008.

Recebido em: 2012-05-06

Aprovado para publicação em: 2013-08-13

Como citar: FARENZENA, Suélen. Costa versus Enel - o primado do direito comunitário e a mudança de paradigma: o Estado em rede Europeu. Revista do Direito Público, Londrina, v.8, n.2, p.173-196, mai/ago.2013. DOI: 10.5433/1980-511X.2013v8n2p173. 